\title{
The Effects of Pre-Pregnancy Body Mass Index and Weight Gain During Pregnancy on Perinatal Outcomes: A Retrospective Cohort Study
}

\author{
Engin YURTCU1, Sibel MUTLU1, Enis OZKAYA² \\ Karabuk, Turkey
}

\section{ABSTRACT}

OBJECTIVE: To investigate the effects of pre-pregnancy body mass index and weight gain during pregnancy on perinatal outcomes and delivery mode.

STUDY DESIGN: In this retrospective cohort study, 722 pregnant women giving birth between 2018-2019 were screened from our hospital database. First, they were divided into four groups according to their prepregnancy body mass index (low-weight/normal-weight/overweight/obese), and then they were redivided into three groups according to pregnancy weight gain $(\leq 7 / 8-15 / \geq 16 \mathrm{~kg})$. Prenatal body mass index and pregnancy weight gain were compared concerning maternal-neonatal results and mode of delivery.

RESULTS: According to pre-pregnancy body mass index, among the obese pregnant group, gestational diabetes mellitus $(p<0.001)$, preeclampsia $(p=0.029)$, preterm delivery $(p=0.011)$ and cesarean delivery $(p=0.061)$ rates were more common. As the body mass index increases, neonatal intensive care requirement $(p=0.0020)$ and low 1 st minute APGAR scores $(p=0.019)$ were detected more frequently. However, as pregnancy weight gain decreased, preterm delivery $(p=0.041)$ increased. Also, birth weight increased $(p<0.001)$ with the weight gain of the pregnant. Pregnant women gaining more than $16 \mathrm{~kg}$ were associated either with a lower $<2500 \mathrm{~g}$ or a higher birth weight risk $>4000 \mathrm{~g}$.

CONCLUSION: Pre-pregnancy high body mass index is associated with negative obstetric outcomes like gestational diabetes, preeclampsia, preterm delivery, and increased cesarean rates, and poor fetal incidences with a low APGAR score and high neonatal intensive care admission rates.

Keywords: Cesarean, Perinatal outcomes, Pre-pregnancy body mass index, Weight gain during pregnancy

Gynecol Obstet Reprod Med 2022;28(1):16-22

\section{Introduction}

Both pre-pregnancy body mass index (BMI) and gestational weight gain may affect maternal and neonatal outcomes. For example, obese women have an increased risk of

\footnotetext{
${ }^{1}$ Departments of Gynecology and Obstetrics, Faculty of Medicine, Karabuk University, Karabuk, Turkey

2 Department of Obstetrics and Gynecology, University of Health Sciences, Zeynep Kamil Women and Children's Health Training and Research Hospital, Istanbul, Turkey

Address of Correspondence: Engin Yurtcu

Ergenekon Mah. Nilufer Sok. Kulepark Sitesi C-Blok D: 11 Merkez 78200, Karabuk

drenginyurtcu1@hotmail.com
}

Submitted for Publication: 04.09.2020 Revised for Publication: 09.09.2020 Accepted for Publication: 22.03.2021 Online Published: 14.04.2021

ORCID IDs of the authors: $\quad$ EY: 0000-0002-1517-3823, SM: 0000-0002-3149-5013, EO: 0000-0001-6580-1237

\begin{tabular}{c|c}
\hline Quick Response Code: & Access this article online \\
\cline { 2 - 2 } & $\begin{array}{c}\text { Website: www.gorm.com.tr } \\
\text { e- mail: infogorm.com.tr }\end{array}$ \\
\cline { 2 - 2 } & DOI:10.21613/GORM.2021.1149 \\
\hline
\end{tabular}

How to cite this article: Yurtcu E. Mutlu S. Ozkaya E. The Effects of PrePregnancy Body Mass Index and Weight Gain During Pregnancy on Perinatal Outcomes: A Retrospective Cohort Study. Gynecol Obstet Reprod Med. 2022;28(1):16-22 many complications during pregnancy, especially gestational diabetes and preeclampsia, and are more likely to have a cesarean delivery (1). Excessive pregnancy weight gain may have similar effects, and may affect the ability of the mother's weight loss and the risk of obesity after childbirth, and may have negative effects on her long-term health (2). The longterm effects of maternal obesity and excessive gestational weight gain on a newborn are also of concern. On the other hand, women who are below normal weight when they become pregnant and have inadequate gestational weight gain are at an increased risk for a small birth of the gestational week, which may have both short and long-term results (3).

Guidelines on appropriate weight gain levels during pregnancy have been published worldwide (4). Although the significance of proper weight and gestational weight gain is well established, many women begin to lose excess weight in pregnancy or most women gain weight during pregnancy (57). In a previous population-based study, obesity was shown to be an independent risk factor for adverse obstetric outcomes and is significantly associated with an increased cesarean delivery rate (8). 
In another study on the impacts of gestational weight on pregnancy outcome, data analysis revealed that obese women with low gestational weight gain had a decreased risk for preeclampsia, cesarean section, instrumental delivery, and large for gestational age (LGA) births. There was a 2-fold increased risk for preeclampsia and LGA infants among average and overweight women with excessive weight gain and high gestational weight gain increased the risk for cesarean delivery in all maternal BMI categorization (3).

The present study aimed to investigate the effects of prepregnancy BMI and weight gain during pregnancy on perinatal outcomes and mode of delivery.

\section{Material and Method}

This retrospective cohort study was conducted between October 2018 and March 2019 in the Gynecology and Obstetrics Clinic of Karabuk University Training and Research Hospital of the Ministry of Health. This study was approved by the local ethics committee of Karabuk University (Ref. No:2020-189). Women with singleton pregnancies who gave birth in the delivery unit of our hospital were included in this study. Pregnant women without adequate records and medical history, births before 24 weeks, multiple pregnancies, pregnant women with severe systemic disease (e.g., diabetes mellitus, chronic hypertension, and chronic kidney failure) were excluded from this study. The records of 722 pregnant women who met these criteria were analyzed retrospectively. Pregnant women were divided into four groups according to the pre-pregnancy BMI; Group 1: Low weight (BMI: $\leq 18.49$ $\mathrm{kg} / \mathrm{m}^{2}$ ), Group 2: Normal weight (BMI: 18.5-24.99 kg/m²), Group 3: Overweight (BMI: 25-29.99 kg/m²), Group 4: obese (BMI: $\geq 30 \mathrm{~kg} / \mathrm{m}^{2}$ ). The pregnant women were also divided into three groups according to the weight gain during pregnancy: Group A: weight gain of seven $\mathrm{kg}$ or less in, Group B: weight gain between eight and 15 kilograms, Group C: weight gain of 16 and over kilograms. The groups were compared concerning maternal demographic parameters, obstetric outcomes (preterm delivery, preeclampsia, gestational hypertension, gestational diabetes mellitus, oligohydramnios, and intrauterine growth restriction (IUGR)), and fetal outcomes (birth weight, APGAR scores of newborn babies, and neonatal intensive care admissions). Pregnant women who had a previous cesarean delivery $(\mathrm{n}=254)$ and who had cesarean delivery due to malpresentation $(n=12)$ were not included in this subgroup to evaluate the risk of cesarean delivery objectively. The following adverse pregnancy outcomes were evaluated: gestational hypertension (blood pressure $>140 / 90 \mathrm{mmHg}$ on at least two occasions greater than six hours apart without evidence of chronic hypertension), preeclampsia (criteria for gestational hypertension and significant proteinuria), gestational diabetes (at least two abnormal values on the 100-g glucose tolerance test following an elevated 50 -g glucose challenge test), preterm premature rupture of membranes (PPROM) (membrane rupture before 37 weeks' gestation), preterm delivery (before 37 weeks gestation), IUGR (estimated fetal weight by ultrasound below the $10^{\text {th }}$ percentile or birth weight below the $10^{\text {th }}$ percentile for gestational age), birth weight greater than $4000 \mathrm{~g}$, and birth weight less than $2500 \mathrm{~g}$.

Minitab package program and $\mathrm{R}$ software were used to perform statistical analyses. Before group comparisons, the compatibility of variables to normal distribution was determined using the Anderson-Darling test. It was determined that the variables did not show normal distribution. To compare groups, the Mann-Whitney U test was used in binary group comparisons, and the Kruskal Wallis test was used in multiple group comparisons. Dunn test was used to determine the different group (or groups) after the Kruskal-Wallis H test. The Chi-Square test was used in the analysis of categorical data. Logistics stepwise regression analysis was performed to analyze the factors that may affect the delivery type. $p<0.05$ was used as a statistical significance level.

\section{Results}

Among 722 pregnant women included in this study, 105 (14.55\%) were obese, $193(26.73 \%)$ were overweight, 378 $(52.35 \%)$ were normal weight, and $46(6.37 \%)$ were in the low BMI group (Table I). Further classification revealed that 126 $(17.45 \%)$ of the pregnant women gained $<8 \mathrm{~kg}, 423(58.58 \%)$ gained $8-15 \mathrm{~kg}$ and $173(23.96 \%)$ gained $16 \mathrm{~kg}$ or more during pregnancy (Table II). The education level in the obese group was lower than the normal BMI group (being a high school and university graduate $34.27 \%$ vs. $57.67 \%$ ). Obese and overweight women were a little older and their parity was higher than normal weight. As the BMI of the pregnancy increased, the mean weight gains during pregnancy decreased.

In obese pregnant group, gestational diabetes mellitus $(p<0.001)$, preeclampsia $(p=0.029)$, preterm delivery $(p=0.011)$ and cesarean delivery $(p=0.061)$ were more common. As the BMI increases, neonatal intensive care requirement $(p=0.002)$ and low minute 1 APGAR score $(p=0.019)$ were detected more frequently. There was no difference between groups concerning oligohydramnios and IUGR rates (Table I). As weight gain decreased during pregnancy, preterm delivery $(p=0.041)$ was found more frequently. As weight gain increased during pregnancy, birth weight increased $(p<0.001)$, and pregnant women with weight gain above $16 \mathrm{~kg}$ (Group C) were associated with lower rates to have a newborn with a birth weight less than $2500 \mathrm{~g}$. On the other hand, higher rates to have a newborn with a birth weight over $4000 \mathrm{~g}$ were more common, but the rates of cesarean, preeclampsia, gestational diabetes mellitus, oligohydramnios, and IUGR were similar (Table II). The logistic regression analysis was performed for the data that might affect the mode of delivery, and we found that the cesarean rates increased as the BMI increased $(p=0.026)$ 
Table I: Comparison of the patients grouped by pre-pregnancy body mass index according to their demographic, clinical characteristics, obstetric, and neonatal outcomes

\begin{tabular}{|c|c|c|c|c|c|}
\hline & $\begin{array}{c}\text { Group } 1 \\
\text { (BMI <18.5) } \\
n=46\end{array}$ & $\begin{array}{c}\text { Group } 2 \\
\text { (BMI 18.5-24.99) } \\
n=378\end{array}$ & $\begin{array}{c}\text { Group } 3 \\
\text { (BMI 25-29.99) } \\
n=193\end{array}$ & $\begin{array}{c}\text { Group } 4 \\
(B M I \geq 30) \\
n=105\end{array}$ & $p$ \\
\hline Age (years) & $26.80 \pm 4.07$ & $27.66 \pm 5.16$ & $29.64 \pm 5.83$ & $30.07 \pm 5.43$ & $<0.001$ \\
\hline Pre-pregnancy BMI $\left(\mathrm{kg} / \mathrm{m}^{2}\right)$ & $17.36 \pm 1.06$ & $22.15 \pm 1.64$ & $27.01 \pm 1.32$ & $34.16 \pm 3.60$ & $<0.001$ \\
\hline Gestational weight gain $(\mathrm{kg})$ & $14.20 \pm 5.76$ & $13.10 \pm 5.04$ & $11.56 \pm 5.28$ & $9.16 \pm 5.92$ & $<0.001$ \\
\hline BMI at delivery $\left(\mathrm{kg} / \mathrm{m}^{2}\right)$ & $22.76 \pm 2.31$ & $27.16 \pm 2.50$ & $31.47 \pm 2.18$ & $37.73 \pm 4.06$ & $<0.001$ \\
\hline Gravidity & $1.93 \pm 1.08$ & $2.25 \pm 1.34$ & $2.62 \pm 1.42$ & $2.64 \pm 1.20$ & $<0.001$ \\
\hline Parity & $0.69 \pm 0.91$ & $1.01 \pm 1.13$ & $1.30 \pm 1.12$ & $1.37 \pm 0.89$ & $<0.001$ \\
\hline Gestational age (weeks) & $38.85 \pm 1.04$ & $38.43 \pm 1.84$ & $38.28 \pm 1.67$ & $38.15 \pm 1.71$ & 0.011 \\
\hline Preterm delivery-n (\%) & $1(2.17)$ & $48(12.69)$ & $24(12.43)$ & $21(20)$ & 0.011 \\
\hline PPROM-n (\%) & $0(0)$ & $9(2.38)$ & $4(2.07)$ & $2(1.9)$ & NA \\
\hline GDM-n (\%) & $1(2.17)$ & $8(2.11)$ & $11(5.69)$ & $16(15.23)$ & $<0.001$ \\
\hline Preeclampsia-n (\%) & $0(0)$ & $10(2.64)$ & $4(2.07)$ & $8(7.61)$ & 0.029 \\
\hline Gestational Hypertension and Preeclampsia-n (\%) & $0(0)$ & $10(2.64)$ & $8(4.14)$ & $9(8.57)$ & 0.018 \\
\hline Birth weight $(\mathrm{g})$ & $3160.5 \pm 426.9$ & $3209.0 \pm 523.3$ & $3242.2 \pm 501.8$ & $3299.5 \pm 533.7$ & 0.294 \\
\hline 1st min APGAR score $\leq 6-n(\%)$ & $0(0)$ & $11(2.91)$ & $3(1.55)$ & $8(7.61)$ & 0.019 \\
\hline 5th min APGAR score $\leq 6-n(\%)$ & $0(0)$ & $2(0.52)$ & $0(0)$ & $1(0.95)$ & NA \\
\hline NICU admission-n (\%) & $1(2.17)$ & $55(14.55)$ & $32(16.58)$ & $25(23.80)$ & 0.002 \\
\hline CS rate-n (\%) & $12(34.29)$ & $85(31.72)$ & $37(35.92)$ & $26(52)$ & 0.061 \\
\hline
\end{tabular}

NICU: Neonatal intensive care unit, BMI: Body mass index, GDM: Gestational diabetes mellitus, CS: Cesarean section, PPROM: Preterm premature rupture of membranes, IUGR: Intrauterine growth restriction, NA: Not applicable

Table II: Comparison of the patients grouped by weight gain during pregnancy according to their demographic, clinical characteristics, obstetric, and neonatal outcomes

\begin{tabular}{|c|c|c|c|c|}
\hline & $\begin{array}{c}\text { Group A } \\
(<8 \mathrm{~kg}) \\
\mathrm{n}=423\end{array}$ & $\begin{array}{c}\text { Group B } \\
(8-15 \mathrm{~kg}) \\
(\geq 16 \mathrm{~kg})\end{array}$ & $\begin{array}{c}\text { Group C } \\
n=126 \\
n=173\end{array}$ & $p$ \\
\hline Age (years) & $28.99 \pm 6.07$ & $28.51 \pm 5.36$ & $28.06 \pm 5.12$ & 0.424 \\
\hline Pre-pregnancy BMI $\left(\mathrm{kg} / \mathrm{m}^{2}\right)$ & $27.35 \pm 6.02$ & $24.86 \pm 4.66$ & $23.33 \pm 4.27$ & $<0.001$ \\
\hline Gestational weight gain $(\mathrm{kg})$ & $4.52 \pm 3.02$ & $11.46 \pm 2.10$ & $19.38 \pm 3.52$ & $<0.001$ \\
\hline BMI at delivery $\left(\mathrm{kg} / \mathrm{m}^{2}\right)$ & $29.11 \pm 5.77$ & $29.28 \pm 4.68$ & $30.72 \pm 4.50$ & $<0.001$ \\
\hline Gravidity & $2.70 \pm 1.54$ & $2.42 \pm 1.33$ & $2.07 \pm 1.16$ & $<0.001$ \\
\hline Parity & $1.42 \pm 1.12$ & $1.15 \pm 1.14$ & $0.82 \pm 0.90$ & $<0.001$ \\
\hline Gestational age (weeks) & $38.09 \pm 1.99$ & $38.34 \pm 1.68$ & $38.68 \pm 1.65$ & 0.013 \\
\hline Preterm delivery-n (\%) & $22(17.46)$ & $58(13.71)$ & $14(8.09)$ & 0.041 \\
\hline PPROM-n (\%) & $3(2.38)$ & $10(2.36)$ & $2(1.15)$ & 0.584 \\
\hline GDM-n (\%) & $12(9.52)$ & $17(4.01)$ & $7(4.04)$ & 0.061 \\
\hline Preeclampsia-n (\%) & $5(3.96)$ & $9(2.12)$ & $8(4.62)$ & 0.230 \\
\hline Gestational Hypertension and Preeclampsia-n (\%) & $6(4.76)$ & $12(2.38)$ & $9(5.20)$ & 0.317 \\
\hline Birth weight (g) & $3079.9 \pm 585.2$ & $3218.8 \pm 491.2$ & $3358.0 \pm 482.2$ & $<0.001$ \\
\hline$<2500$ g-n (\%) & $19(15.07)$ & $32(7.56)$ & $4(2.31)$ & \\
\hline \multicolumn{5}{|l|}{$<0.001$} \\
\hline 2500-3999 g-n (\%) & $99(78.57)$ & $370(87.47)$ & $153(88.43)$ & \\
\hline$\geq 4000$ g-n (\%) & $8(6.34)$ & $21(4.96)$ & $16(9.24)$ & \\
\hline $1^{\text {st }} \min$ APGAR score $\leq 6-n(\%)$ & $6(4.76)$ & $13(3.07)$ & $3(1.73)$ & 0.322 \\
\hline $5^{\text {th }} \min$ APGAR score $\leq 6-n(\%)$ & $1(0.79)$ & $1(0.23)$ & $1(0.57)$ & NA \\
\hline NICU admission & $24(19.04)$ & $65(15.36)$ & $24(13.87)$ & 0.473 \\
\hline CS rate-n (\%) & $26(35.62)$ & $90(34.35)$ & $44(36.36)$ & 0.924 \\
\hline
\end{tabular}

NICU: Neonatal intensive care unit, BMI: Body mass index, GDM: Gestational diabetes mellitus, CS: Cesarean section, PPROM: Preterm premature rupture of membranes, IUGR: Intrauterine growth restriction, NA: Not applicable 
Table III showed the results of the groups and subgroups grouped by pre-pregnancy BMI and weight gain during pregnancy, respectively. Preterm birth, gestational diabetes mellitus, preeclampsia, and 1 st minute low APGAR score rates were insignificantly higher in Group 4C included patients who were obese and excessive weight gain during pregnancy $(\geq 16$ $\mathrm{kg}$ ) than all other groups. In Group 2, pre-pregnancy normal weight group, the rate of preterm delivery increased as weight gain decreased during pregnancy $(p=0.008)$ (Table III).

\section{Discussion}

Obesity is determined in women with BMI $\geq 30 \mathrm{~kg} / \mathrm{m}^{2}$ (9) and based on this cut-off value, different classes have been introduced to determine risk category as Class I (BMI 30.0 to $34.9 \mathrm{~kg} / \mathrm{m}^{2}$ ), class II (BMI 35.0 to $39.9 \mathrm{~kg} / \mathrm{m}^{2}$ ), and class III $\left(\mathrm{BMI} \geq 40 \mathrm{~kg} / \mathrm{m}^{2}\right)$. All these cut-off values and classifications were established for the non-pregnant population and do not adapt well to the pregnant population. Thus, it is crucial to consider pregnant women to be obese or non-obese based on their pre-pregnancy BMI. In our study, we assessed the impacts of both pre-pregnancy BMI and weight gain during pregnancy on perinatal outcomes to overcome inconsistency in the classification of BMI in pregnant women. Obesity was shown to be modestly increased the risk of early pregnancy loss. In a systematic review, including six retrospective studies, in 28,538 women (10), obesity was associated with the risk of miscarriage. Additional data confirmed this increased risk in this population and revealed that obese women with a history of recurrent miscarriage were at increased risk of future pregnancy loss compared with women with a normal BMI (11). However, both reviews had high heterogeneity for the included studies. Given that we aimed to assess both maternal and neonatal outcomes, we did not include pregnant women with early miscarriages. Another pregnancy complication that was mostly discussed in the literature is gestational diabetes. The risk of developing gestational diabetes mellitus (GDM) was significantly higher in obese women than in the general obstetric population $(12,13)$, and this risk increased with increasing maternal weight and BMI $(14,15)$. In a systematic review of studies on pre-pregnancy BMI and risk of GDM, the prevalence of GDM increased by 0.92 percent for every $1 \mathrm{~kg} / \mathrm{m}^{2}$ increase in BMI (16). As we presented in our results, maternal BMI was also an independent risk factor for both preeclampsia and gestational hypertension (17-23). Consistently, a very well-organized systematic review of 13 cohort studies comprising nearly 1.4 million women revealed that the risk of preeclampsia doubled with each five to seven $\mathrm{kg} / \mathrm{m} 2$ increase in pre-pregnancy BMI (20). In our study population, pre-pregnancy BMI was associated with preeclampsia.

Several pregnancy complications may lead to an iatrogenically increased rate of premature deliveries, and prematurity is the main risk factor for neonatal deaths. Pre-pregnancy obesity is also associated with hypertension, preeclampsia, and diabetes and indirectly increases the risk of medically indi-

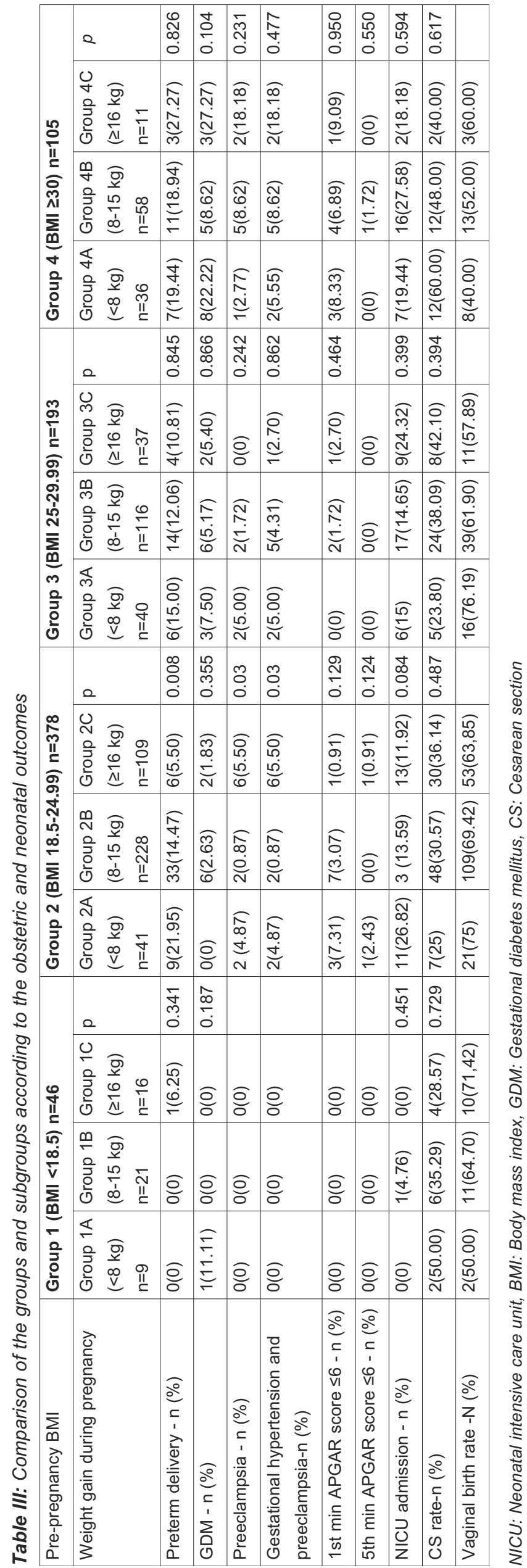


cated preterm delivery. In a systematic review on this issue, overweight and obese women were at an increased risk of induced preterm birth compared with women of normal BMI (24). There is some evidence that pre-pregnancy obesity may also prolong pregnancy (25), but the mechanism has not been determined yet. Although obesity was shown to be a risk factor for prolonged labor, the duration of the second stage of labor did not appear to be affected by increasing BMI $(26,27)$. As a consequence of all these pregnancy complications, obesity was also a risk factor for both elective and emergency cesarean delivery (28). Obesity-related pregnancy complications, such as higher infant birth weight, increased frequency of preterm and post-term delivery, were reported to be major confounders for the excess risk of cesarean delivery (29).

The Committee on Nutritional Status during Pregnancy and Lactation of the Institute of Medicine analyzed all published data regarding the relationship between pre-pregnancy weight, weight gain during pregnancy, and pregnancy outcome. Based on that analysis, some recommendations have been introduced for healthy gestation (30). These recommendations aimed to prepare pregnant to deliver a term live-born infant with a birth weight between 3000 and $4000 \mathrm{~g}$. Recommendations for gestational weight gain were established based on pre-pregnancy body mass index. Therefore, it was suggested that determining BMI before pregnancy should be an integral part of the physical examination of pregnant women. Studies have suggested that women with class II or III obesity might benefit from lower weight gain target ranges than women with class I obesity (31-33). In our study, we found negatively correlated pre-pregnancy BMI and weight gain during pregnancy.

Gestational weight gain above suggested values has been associated with an increased risk of macrosomia and large for gestational age (LGA) infants, a cesarean delivery (34), pregnancy-related hypertension (gestational hypertension, preeclampsia) (35-39), and gestational diabetes (40). A systematic review revealed that high gestational weight gain was associated with a lower risk of preterm birth and small for gestational age, higher risk of LGA and macrosomia, and cesarean delivery compared with women whose gestational weight gain within the recommended range (34).

In a recently published study conducted on the Turkish population, the authors showed that gestational mean weight gain was $10.7 \mathrm{~kg}$ in the group with gestational diabetes, whereas it was $7.9 \mathrm{~kg}$ in the control group. In this study, prepregnancy body weights were also significantly different between the two groups ( $72 \mathrm{~kg}$ vs. $60 \mathrm{~kg}, \mathrm{p}<0.001$ ). Predictive values of pre-pregnancy weight and gestational weight gains for gestational diabetes were well documented in this study; however, no data were presented regarding pregnancy complications and outcomes (41). Our study had a higher number of pregnant to evaluate these differences compared to that study.
There were also some limitations in our study. The retrospective nature of this study was the main limitation. We could not evaluate the other possible risk factors that might be associated with gestational diabetes and preeclampsia, such as family history and previous pregnancy outcomes. The patients were divided into subgroups according to their prepregnancy BMI and weight gain during pregnancy. The patient distribution between the subgroups was not similar. Additionally, the higher number of patients may be the strength of the current study.

In conclusion, pre-pregnancy high BMI is associated with negative obstetric outcomes, such as gestational diabetes, preeclampsia, preterm delivery and increased cesarean rates, and poor fetal outcomes with low APGAR score and high neonatal intensive care admission rate. The findings suggest that there is a strong relationship between weight gain during pregnancy and birth weight. It should be ensured that candidates who are overweight and obese should be directed to weight control by considering the risks of pregnancy and management should be individualized.

Acknowledgment: We would like to thank Dr. Seyit Ali Kayls for his valuable suggestions regarding the statistical analysis and interpretation of results. This study has been presented in the $4^{\text {th }}$ International Pregnancy, Birth and Postpartum Congress in Bolu, Turkey as an oral presentation date 2023/02/2020.

Conflict of interest: The authors have no conflict interests to declare.

Funding: None.

Consent to participate: All participants signed informed written consent before being enrolled in the study.

Availability of data and materials: The data supporting this study is available through the corresponding author upon reasonable request. The datasets and code used and/or analyzed during the current study are available from the corresponding author on reasonable request.

Authors' contributions: EY. researched literature and conceived the study. EY. and SM. were involved in protocol development, gaining ethical approval, patient recruitment, and data analysis. EO. and EY. did the critical revision of the article. EY. and EO. wrote the first draft of the manuscript. All authors reviewed and edited the manuscript and approved the final version of the manuscript.

\section{References}

1. Schummers L, Hutcheon JA, Bodnar LM, Lieberman E, Himes KP. Risk of adverse pregnancy outcomes by prepregnancy body mass index: a population-based study to inform prepregnancy weight loss counseling. Obstet Gynecol. 2015;125(1):133-43. Doi: 10.1097/AOG.00000 00000000591.

2. Rooney BL, Schauberger CW. Excess pregnancy weight gain and long-term obesity: one decade later. Obstet 
Gynecol. 2002;100(2):245-52. Doi: 10.1016/s0029-7844 (02)02125-7.

3. Cedergren M. Effects of gestational weight gain and body mass index on obstetric outcome in Sweden. Int $\mathrm{J}$ Gynaecol Obstet. 2006;93(3):269-74. Doi: 10.1016/j.ijgo. 2006.03.002.

4. Alavi N, Haley S, Chow K, McDonald SD. Comparison of national gestational weight gain guidelines and energy intake recommendations. Obes Rev. 2013;14(1):68-85. Doi: 10.1111/j.1467-789X.2012.01059.x.

5. Chung JG, Taylor RS, Thompson JM, Anderson NH, Dekker GA, Kenny LC, et al. Gestational weight gain and adverse pregnancy outcomes in a nulliparous cohort. Eur J Obstet Gynecol Reprod Biol. 2013;167(2):149-53. Doi: 10.1016/j.ejogrb.2012.11.020.

6. Daemers DO, Wijnen HA, van Limbeek EB, Budé LM, de Vries RG. Patterns of gestational weight gain in healthy, low-risk pregnant women without co-morbidities. Midwifery. 2013;29(5):535-41. Doi: 10.1016/j.midw. 2012.04.012.

7. Ferraro ZM, Barrowman N, Prud'homme D, Walker M, Wen SW, Rodger M, et al. Excessive gestational weight gain predicts large for gestational age neonates independent of maternal body mass index. J Matern Fetal Neonatal Med. 2012;25(5):538-42. Doi:10.3109/147670 58.2011 .638953 .

8. Weiss JL, Malone FD, Emig D, Ball RH, Nyberg DA, Comstock $\mathrm{CH}$, et al. Obesity, obstetric complications and cesarean delivery rate--a population-based screening study. Am J Obstet Gynecol. 2004;190(4):1091-7. Doi: 10.1016/j.ajog.2003.09.058.

9. ACOG Practice Bulletin No 156: Obesity in Pregnancy. Obstet Gynecol. 2015;126(6):e112-e126. Doi: 10.1097/ AOG.0000000000001211. Erratum in: Obstet Gynecol. 2016;128(6):1450. PMID: 26595582.

10. Boots C, Stephenson MD. Does obesity increase the risk of miscarriage in spontaneous conception: a systematic review. Semin Reprod Med. 2011;29(6):507-13. Doi: 10. 1055/s-0031-1293204.

11. Cavalcante MB, Sarno M, Peixoto AB, Junior EA, Barini R. Obesity and recurrent miscarriage: A systematic review and meta-analysis. J Obstet Gynaecol Res. 2019;45(1):308. Doi: $10.1111 /$ jog. 13799.

12. Ehrenberg HM, Dierker L, Milluzzi C, Mercer BM. Prevalence of maternal obesity in an urban center. Am J Obstet Gynecol. 2002;187(5):1189-93. Doi: 10.1067/ mob.2002.127125.

13. Gross T, Sokol RJ, King KC. Obesity in pregnancy: risks and outcome. Obstet Gynecol. 1980;56(4):446-50. PMID: 7422189.

14. Sebire NJ, Jolly M, Harris JP, Wadsworth J, Joffe M, Beard RW, et al. Maternal obesity and pregnancy outcome: a study of 287,213 pregnancies in London. Int J
Obes Relat Metab Disord. 2001;25(8):1175-82. Doi: 10.1038/sj.ijo.0801670.

15. Chu SY, Callaghan WM, Kim SY, Schmid CH, Lau J, England LJ, et al. Maternal obesity and risk of gestational diabetes mellitus. Diabetes Care. 2007;30(8):2070-6. Doi: $10.2337 / \mathrm{dc} 06-2559 \mathrm{a}$.

16. Torloni MR, Betrán AP, Horta BL, Nakamura MU, Atallah AN, Moron AF, et al. Prepregnancy BMI and the risk of gestational diabetes: a systematic review of the literature with meta-analysis. Obes Rev. 2009;10(2):194203. Doi: 10.1111/j.1467-789X.2008.00541.x.

17. Robinson HE, O’Connell CM, Joseph KS, McLeod NL. Maternal outcomes in pregnancies complicated by obesity. Obstet Gynecol. 2005;106(6):1357-64. Doi: 10.1097/01.AOG.0000188387.88032.41.

18. Sibai BM, Gordon T, Thom E, Caritis SN, Klebanoff M, McNellis D, et al. Risk factors for preeclampsia in healthy nulliparous women: a prospective multicenter study. The National Institute of Child Health and Human Development Network of Maternal-Fetal Medicine Units. Am J Obstet Gynecol. 1995;172(2 Pt 1):642-48. Doi: 10.1016/0002-9378(95)90586-3.

19. Sibai BM, Ewell M, Levine RJ, Klebanoff MA, Esterlitz $\mathrm{J}$, Catalano PM, et al. Risk factors associated with preeclampsia in healthy nulliparous women. The Calcium for Preeclampsia Prevention (CPEP) Study Group. Am J Obstet Gynecol. 1997;177(5):1003-10. Doi: 10.1016/ s0002-9378(97)70004-8.

20. O’Brien TE, Ray JG, Chan WS. Maternal body mass index and the risk of preeclampsia: a systematic overview. Epidemiology. 2003;14(3):368-74. Doi: 10.1097/0000164 8-200305000-00020.

21. HAPO Study Cooperative Research Group. Hyperglycaemia and Adverse Pregnancy Outcome (HAPO) Study: associations with maternal body mass index. BJOG. 2010;117(5):575-84. Doi: 10.1111/j.1471-0528.2009. 02486.x.

22. Gaillard R, Steegers EA, Hofman A, Jaddoe VW. Associations of maternal obesity with blood pressure and the risks of gestational hypertensive disorders. The Generation R Study. J Hypertens. 2011;29(5):937-44. Doi: 10.1097/HJH.0b013e328345500c.

23. Stuebe AM, Landon MB, Lai Y, Spong CY, Carpenter MW, Ramin SM, et al. Maternal BMI, glucose tolerance, and adverse pregnancy outcomes. Am J Obstet Gynecol. 2012;207(1):62.e1-7. Doi: 10.1016/j.ajog.2012.04.035.

24. McDonald SD, Han Z, Mulla S, Beyene J; Knowledge Synthesis Group. Overweight and obesity in mothers and risk of preterm birth and low birth weight infants: systematic review and meta-analyses. BMJ. 2010;341:c3428. Doi: 10.1136/bmj.c3428.

25. Usha Kiran TS, Hemmadi S, Bethel J, Evans J. Outcome of pregnancy in a woman with an increased body mass index. BJOG. 2005;112(6):768-72. Doi: 10.1111/j.1471- 
0528.2004.00546.x.

26. Vahratian A, Zhang J, Troendle JF, Savitz DA, Siega-Riz AM. Maternal prepregnancy overweight and obesity and the pattern of labor progression in term nulliparous women. Obstet Gynecol. 2004;104(5 Pt 1):943-51. Doi: 10.1097/01.AOG.0000142713.53197.91.

27. Robinson BK, Mapp DC, Bloom SL, Rouse DJ, Spong CY, Varner MW, et al. Increasing maternal body mass index and characteristics of the second stage of labor. Obstet Gynecol. 2011;118(6):1309-13. Doi: 10.1097/ AOG.0b013e318236fbd1.

28. Brost BC, Goldenberg RL, Mercer BM, Iams JD, Meis PJ, Moawad AH, et al. The Preterm Prediction Study: association of cesarean delivery with increases in maternal weight and body mass index. Am J Obstet Gynecol. 1997; 177(2):333-7. Doi: 10.1016/s0002-9378(97)70195-9.

29. Owens LA, O’Sullivan EP, Kirwan B, Avalos G, Gaffney G, Dunne F, et al. ATLANTIC DIP: the impact of obesity on pregnancy outcome in glucose-tolerant women. Diabetes Care. 2010;33(3):577-9. Doi:10.2337/dc090911.

30. Institute of Medicine (US), Food and Nutrition Board, Committee on Nutritional Status During Pregnancy, part I: Nutritional Status and Weight Gain. Washington, DC: National Academy Press; 2000. Doi: 10.17226/1451.

31. Furber CM, McGowan L, Bower P, Kontopantelis E, Quenby S, Lavender T. Antenatal interventions for reducing weight in obese women for improving pregnancy outcome. Cochrane Database Syst Rev. 2013;(1):CD009334. Doi: 10.1002/14651858.CD009334.pub2.

32. Kapadia MZ, Park CK, Beyene J, Giglia L, Maxwell C, McDonald SD. Weight loss instead of weight gain within the guidelines in obese women during pregnancy: a systematic review and meta-analyses of maternal and infant outcomes. PLoS One. 2015;10(7):e0132650. Doi:10. 1371/journal. pone. 0132650 .

33. Beyerlein A, Schiessl B, Lack N, von Kries R. Associations of gestational weight loss with birth-related outcome: a retrospective cohort study. BJOG. 2011;118
(1):55-61. Doi: 10.1111/j.1471-0528.2010.02 761.x.

34. Goldstein RF, Abell SK, Ranasinha S, Misso M, Boyle JA, Black MH, et al. Association of gestational weight gain with maternal and infant outcomes: a systematic review and meta-analysis. JAMA. 2017;317(21):2207-25. Doi: 10.1001/jama.2017.3635.

35. Johnson J, Clifton RG, Roberts JM, Myatt L, Hauth JC, Spong CY, et al. Pregnancy outcomes with weight gain above or below the 2009 Institute of Medicine guidelines. Obstet Gynecol. 2013;121(5):969-75. Doi: 10.1097/ AOG.0b013e31828aea03.

36. de la Torre L, Flick AA, Istwan N, Rhea D, Cordova Y, Dieguez $\mathrm{C}$, et al. The effect of new antepartum weight gain guidelines and prepregnancy body mass index on the development of pregnancy-related hypertension. Am J Perinatol. 2011;28(4):285-92. Doi: 10.1055/s-0030-127 1211.

37. Macdonald-Wallis C, Tilling K, Fraser A, Nelson SM, Lawlor DA. Gestational weight gain as a risk factor for hypertensive disorders of pregnancy. Am J Obstet Gynecol. 2013;209(4):327:e1-17. Doi: 10.1016/j.ajog. 2013.05.042.

38. Truong YN, Yee LM, Caughey AB, Cheng YW. Weight gain in pregnancy: does the Institute of Medicine have it right? Am J Obstet Gynecol. 2015;212(3):362.e1-8. Doi: 10.1016/j.ajog.2015.01.027.

39. Kominiarek MA, Saade G, Mele L, Bailit J, Reddy UM, Wapner RJ, et al. Association between gestational weight gain and perinatal outcomes. Obstet Gynecol. 2018;132 (4):875-81. Doi: 10.1097/AOG.0000000000002854.

40. Hedderson MM, Gunderson EP, Ferrara A. Gestational weight gain and risk of gestational diabetes mellitus. Obstet Gynecol. 2010;115(3):597-04. Doi: 10.1097/ AOG.0b013e3181cfce4f.

41. Takmaz T, Yalvaç ES, Ozcan P, Coban U, Gokmen Karasu AF. Unsal M. The predictive value of weight gain and waist circumference for gestational diabetes mellitus. Turk J Obstet Gynecol. 2019;16(3):199-204. Doi: 10. 4274/tjod.galenos.2019.03266. 